\title{
A quantitative indirect immunofluorescent assay for zona pellucida antibodies
}

\author{
P. L. Nayudu, L. E. Freemann and A. O. Trounson \\ Department of Obstetrics and Gynaecology, Monash University, Queen Victoria Medical \\ Centre, 172 Lonsdale Street, Melbourne, 3000 Victoria, A ustralia
}

\begin{abstract}
Summary. A dilution series of a standard antiserum, raised in rabbit, against intact porcine oocytes was tested by an indirect immunofluorescent assay under a variety of conditions. Maximal antibody binding was obtained in phosphate-buffered saline with sucrose and sodium azide as a serum diluent and wash buffer, with relatively long incubation and wash periods, and in some cases heat-inactivation of sera.

Factors found to influence the antibody binding were: alteration of the zonae by fixation; the presence of sucrose, galactose or glycerol; addition of protein to the buffer; heat inactivation of serum; substitution of phosphate by borate buffer; and replacement of the labelled second antibody by labelled Protein A. Antisera produced against acid- and heat-solubilized zonae differed from the standard antiserum in their binding capacity. Control sera (anti-porcine spleen, adjuvant injected, and normal) were all completely negative.
\end{abstract}

\section{Introduction}

The immunogenicity of the zona pellucida (zona), and the possible role of specific antibodies in infertility and contraception has received considerable attention (Gwatkin, Williams \& Carlo, 1977; Shivers, Genozian, Franklin \& McLaughlin, 1978; Tsunoda \& Sugie, 1979; Trounson, Shivers, McMaster \& Lopata, 1980). This work has been hampered, however, by lack of quantitative assay for antibody binding and by lack of detailed knowledge of zona biochemistry. Most reports of zona antibody binding have used immunofluorescence or light scattering by the antigen-antibody complex as the means of detection. Some degree of quantitation has been achieved by end-point titration or a system of plus-minus scores based on visual estimation (Oikawa \& Yanagimachi, 1975; Yanagimachi, Winkelhake \& Nicholson, 1976; Gwatkin et al., 1977; Gwatkin \& Williams, 1978; Shivers et al., 1978; Trounson et al., 1980). Tsunoda, Sugie \& Mori (1979) have systematically compared end-point titres of assay methods for the zona precipitate, indirect immunofluorescence, time of zona dissolution, and inhibition of in-vitro fertilization: fluorescence was the most sensitive of the four methods.

Assays have also been reported in which fluorescence (Gerrity, Niu \& Dunbar, 1980) or radioactivity (Dunbar \& Raynor, 1979; Palm, Sacco, Syner \& Subramanian, 1979) has been accurately measured. In spite of these improvements in quantitation, there is still a need for new methods giving accurate titration of zona pellucida antisera. The present paper describes a new indirect immunofluorescent assay method in which the fluorescence is quantitated by microspectrofluorometry. 


\section{Materials and Methods}

\section{Buffers}

The standard assay buffer was phosphate $\left(\mathrm{Na}_{2} \mathrm{HPO}_{4}\right.$ and $\left.\mathrm{KH}_{2} \mathrm{PO}_{4}\right)$-buffered saline (PBS) $(280$ mosmol and $\mathrm{pH} \mathrm{7.2).} \mathrm{It} \mathrm{was} \mathrm{used} \mathrm{alone} \mathrm{or} \mathrm{with} \mathrm{the} \mathrm{additives} \mathrm{listed} \mathrm{below.} \mathrm{Borate-buffered}$ saline $\left(\mathrm{Na}_{2} \mathrm{~B}_{4} \mathrm{O}_{7} \cdot 10 \mathrm{H}_{2} \mathrm{O}\right.$ and $\left.\mathrm{H}_{3} \mathrm{BO}_{3}\right)(274$ mosmol, $\mathrm{pH} 7 \cdot 4)$ was used as a medium in which carbohydrate-protein interactions leading to binding are suppressed (Svensson, Hammarström \& Kabat, 1970).

\section{Buffer additives}

Sucrose $(0.05 \mathrm{M})$ (Analar: British Drug Houses, Kew, Victoria, Australia) was prepared by heating in PBS to avoid fine crystals in the solution. Galactose $(0.05 \mathrm{M})$ (Sigma grade: Sigma Chemical Co., St Louis, Missouri, U.S.A.) was made up in the same way as the sucrose solution in PBS buffer. Sodium azide (Lab. Chem., Ajax Chemicals, Auburn, New South Wales, Australia) was tested in concentrations from 0.001 to $4 \%(0.00015$ to $0.615 \mathrm{M})$ in PBS. Bovine serum albumin, BSA (B grade, Calbiochem, Behring Carlingford, New South Wales, Australia), was used in concentrations from 0.1 to $8 \%$ in PBS.

\section{Fluorescence-labelled binding proteins}

Fluorescein isothiocyanate (FITC)-conjugated goat IgG, produced against rabbit IgG (Nordic Immunological Laboratories, Tilburg, The Netherlands), and FITC-conjugated Protein A (Pharmacia Fine Chemicals, North Ryde, New South Wales, Australia) were both used as indirect immunofluorescent tracers.

\section{Cryoprotectant}

To reduce cracking of zona during freezing, a cryoprotectant buffer of $0.81 \mathrm{M}$-glycerol, 0.05 M-sucrose in PBS was used.

\section{Serum treatments}

Heat inactivation was carried out in a $56^{\circ} \mathrm{C}$ water bath for $35 \mathrm{~min}$. Adsorptions were carried out with porcine erythrocytes, spleen and liver cells. Tissue cells were first separated by glass homogenization in cold PBS. The cells were washed 4 times in PBS. Between washings the cells were centrifuged to form a pellet and the supernatant was discarded. Antiserum was mixed 1/1 with cells and allowed to stand at room temperature for $1 \mathrm{~h}$ with occasional mixing. The mixture was centrifuged and the supernatant taken for use in the assay.

\section{Oocyte collection}

Porcine ovaries were obtained from a local abattoir and were transported to the laboratory on ice within $1 \mathrm{~h}$. The oocytes were collected by a method developed in this laboratory. Two florists pin holders were used to prick the follicles. The follicular fluid and the ovaries were briefly shaken in 0.01 M-sodium citrate in PBS and then poured through a set of sieves made of plankton nets (Dunbar, Wardrip \& Hedrick, 1980). The nets were washed in the same buffer in a Petri dish and then oocytes were collected from the dish with a fine-drawn Pasteur pipette. Only mature apparently undegenerated oocytes were retained for use in the assay. 


\section{Oocyte treatments}

Oocytes were frozen in cryoprotectant in liquid nitrogen. Some oocytes were fixed in $3.7 \%$ paraformaldehyde (BDH) in PBS for $30 \mathrm{~min}$ before tests of the effect of fixation on the assay results. To produce heat-solubilized zonae, oocytes held in a small container in PBS were heated in a $500 \mathrm{ml}$ water bath in which the temperature was allowed to fall from an initial $90^{\circ} \mathrm{C}$ to $\sim 22^{\circ} \mathrm{C}$. Zonae pellucidae were acid-solubilized from intact oocytes with acidified PBS (pH 3, $0.1 \mathrm{M}-\mathrm{HCl}$ added dropwise until the desired $\mathrm{pH}$ was obtained). In both cases the oocytes were subsequently sedimented in a bench centrifuge and the supernatant was removed for use.

\section{Antibody production}

The antibody production was carried out according to a modification of Vaitukaitis, Robbins, Nieschlag \& Ross (1971). Two rabbits were used for each antigenic preparation. Each immunization was carried out by injecting 3000 clean whole porcine oocytes, heat-solubilized zonae, or acid-solubilized zonae. The adjuvants (all obtained from Commonwealth Serum Laboratories, Melbourne, Victoria, Australia) were emulsified with the antigen and injected intradermally. The doses were $6 \mathrm{mg}$ bacille Calmette-Guérin vaccine (BCG) and $1 \mathrm{ml}$ Freund's complete adjuvant per rabbit. Bordetella pertussis vaccine $(0.5 \mathrm{ml})$ was injected subcutaneously at one site.

Control immunizations were adjuvants only and $0.4 \mathrm{~g}$ porcine spleen injected with the same combination of adjuvants. Normal rabbit serum was used as a negative control. The immunized rabbits were given a booster injection of the same amount of antigen emulsified with $1 \mathrm{ml}$ incomplete Freund's adjuvant after 6 weeks, and then bled 2 weeks after that. Antisera to oocytes or solubilized zonae were tested and the one in each category showing the highest end-point titre was used throughout the work. The sera were not purified.

\section{Assay method}

The oocytes used as antigen in the assay were contained in a cup with a plankton net base constructed from the cap of a plastic microfuge tube (Text-fig. 1). This permitted handling of the oocytes as a group and made solution changes easier. The container and the solutions were held

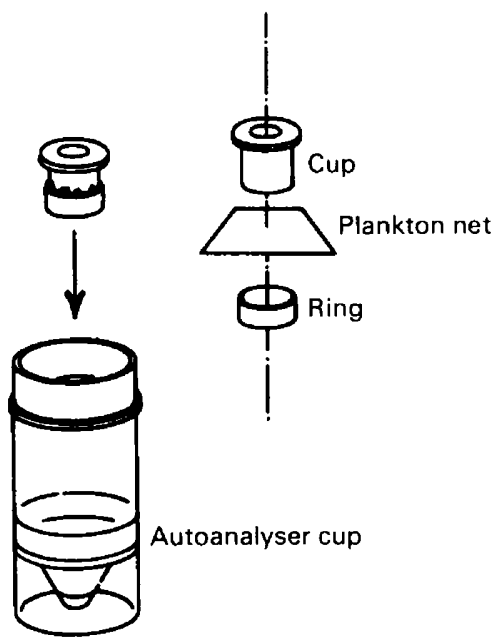

Text-fig. 1. Oocyte container used to facilitate transfers during assay; shown as separate components and assembled with autoanalyser cup used to hold assay solutions. 
in a plastic microfuge cup. The sequential incubations and washes of the oocytes were as follows in the 4-day assay: (1) $16 \mathrm{~h}$ at $4^{\circ} \mathrm{C}$ in antiserum diluted with buffer, (2) $24 \mathrm{~h}$ at $4{ }^{\circ} \mathrm{C}$ in excess buffer, (3) $4 \mathrm{~h}$ at room temperature in FITC-anti-rabbit IgG or FITC-Protein A, and (4) $20 \mathrm{~h}$ at $4^{\circ} \mathrm{C}$ in excess buffer. In a 3 -day assay the times were $16,4,4$ and $16 \mathrm{~h}$ respectively. Incubation was carried out by immersion of the oocytes in the appropriate medium, without agitation. Between changes, the cups were placed on blotting paper, to avoid carry-over of fluid.

The assay was read coded the next morning. Oocytes were placed on microscope slides in a drop of buffer under a wax-sealed coverslip. Zona fluorescence was detected, measured and photographed on a Leitz Orthoplan 2 microscope with Ploemopak fluorescent filter set D which has an emission range from u.v. to violet. The light source was a stabilized Osram $150 \mathrm{~W}$ Xenon high pressure lamp. The fluorescence was detected by an EMI photomultiplier attached to an ultrastabilized high voltage supply and measured by a Fluke $8000 \mathrm{~A}$ digital multimeter. Excitation time, $10 \mathrm{sec}$, was controlled by a shutter device. All settings were standardized. At least 6 oocytes were measured individually and corrections were made for differences in diameter. A positive zona-antibody reaction was identified by an even fluorescent ring at the surface of the zona. A negative reaction was indicated by the lack of a ring.

\section{Fluorescence unit standards}

Two antiserum standards and their blanks were run with each assay. Both were 4-day assays with intact oocyte antiserum and normal serum at 1:50 dilution. One set was in PBS and the other in sucrose-PBS. The sucrose-PBS standard was calculated to be 0.5 fluorescence units relative to the theoretical maximum of 1 . Test values were adjusted relative to the sucrose standard, to correct for minor variation in values.

\section{Analysis of results}

The analysis was carried out on the University central computer. The logit, $\log _{e}$ conversion was used as the plotting method (Text-figs 3,5 and 6), being the most effective for linearization of the data. The regressions were plotted for that portion of the original data which could be linearized. Non-significant or non-linear regressions are not presented graphically. Serum dilutions $1: 5$ to $1: 400$, treated as fractions, were decimalized and converted to $\log _{e}$. Fluorescence units were converted to logit. A correction was incorporated for the fluorescence of normal serum controls, so that $\operatorname{logit}=\log _{e} \mathrm{P}-\mathrm{C}_{1} / \mathrm{C}_{2}-\mathrm{P}$ where $\mathrm{P}=y / y_{\max } \mathrm{C}_{1}=y_{\min }$ (normal serum fluorescence) and $\mathrm{C}_{2}=y_{\max }$ (standardized highest fluorescence $=1$ ).

This and other analyses, such as analysis of variance, regression, linearity, standard deviation and parallelism (determined by multiway analysis of variance), were all carried out according to Borth (1960). The index of precision $\lambda=s / b$, where $s=$ standard deviation of the regression and $b=$ slope (Borth, 1960; Cornfield, 1970). The equation, $s_{y}=s_{\text {logit }} / \sqrt{x_{1}^{2}+x_{2}{ }^{2}}$ can be used to convert standard deviation in logit to $y$ units where $x_{1}=1 / y-\mathrm{C}_{1}$ and $x_{2}=1 / \mathrm{C}_{2}-y$. The simplifying assumption is made that the $s$ is equal on both sides of the regression and along the $x$ axis.

\section{Results}

Antiserum of the highest titre produced by injection of whole oocytes was used throughout the optimization. Others of lower titre showed the same binding properties but produced overall lower fluorescence. The assay is presented in two time variations, the 4-day and the 3-day. Oocyte number and the volume of anti-zona serum were systematically varied. The optimal combination chosen for routine use was 20 oocytes and $100 \mu \mathrm{l}$ serum. The effect of freezing the 
oocytes at various stages before and during the assay was determined (Text-fig. 2). Cryoprotectant was removed from oocytes before the assay solution was added. Oocytes not frozen and those frozen only just before the assay produced insignificantly different results. Any interruption of the assay by frozen storage of the oocytes tended to reduce the final fluorescence. The duration over which oocytes remained frozen did not influence the result. Therefore, oocyte freezing was used only for preassay storage to avoid the necessity of fresh oocyte collection on the first day of an assay.

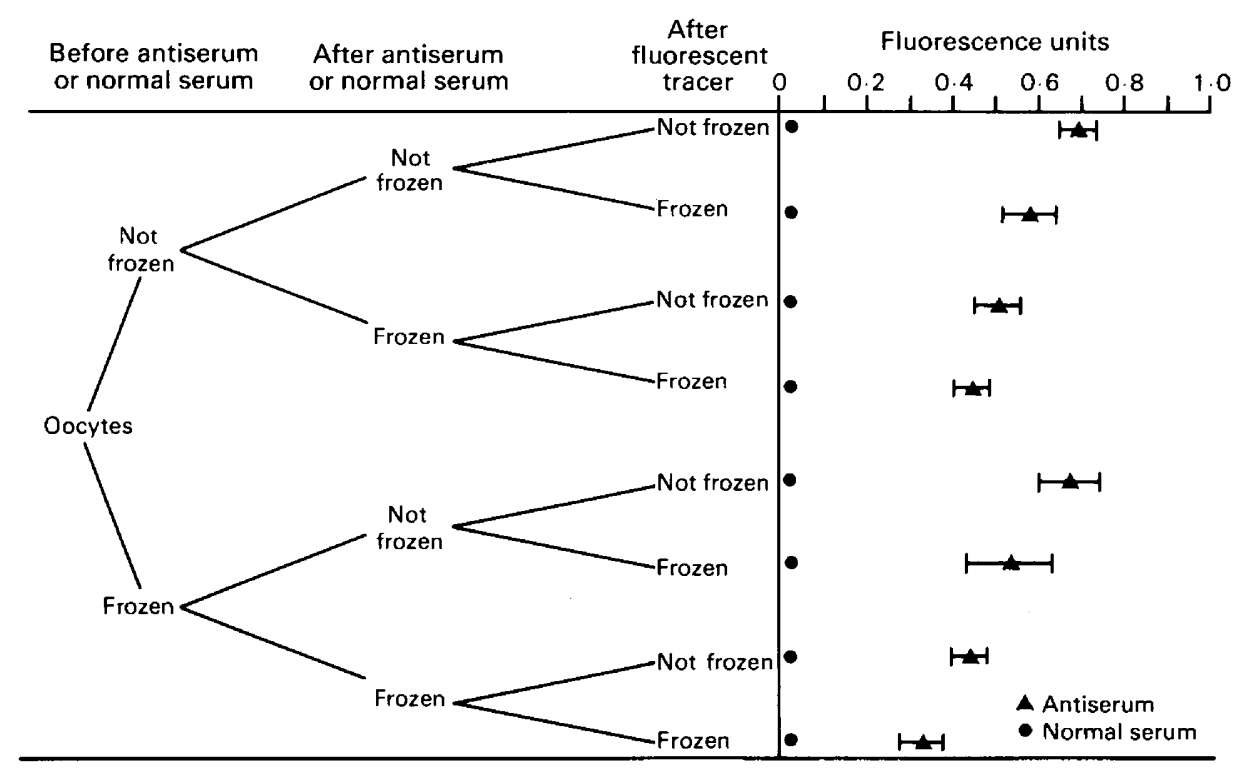

Text-fig. 2. Effect of oocyte freezing at various stages in the assay; standard 4-day conditions, serum dilution $1: 50$. Values are means \pm s.e.m. for 6 oocytes.

\section{The 4-day assay}

FITC-conjugated IgG and Protein A were used at optimal concentrations as determined for each batch. The oocytes treated with normal serum never exhibited a zona coating of serum protein. The generalized insignificant level of fluorescence present with normal sera was relatively constant $(0.02$ fluorescence units) at low protein concentrations.

The assay conducted in PBS was used as a standard of comparison for the changes induced by the presence of other additives to the system. Standard 4-day assay conditions included visualization by IgG-FITC, with sodium azide and sucrose in the buffer. The addition of sucrose to the buffer reduced the standard deviation and thereby improved the precision of the assay (Text-fig. 3a). The reduced slope with sucrose indicates a greater sensitivity at low antibody concentrations. The presence of glycerol or BSA significantly inhibited the fluorescence over the entire antiserum dilution range (Text-fig. 3b). Sucrose was able to counteract the glycerol effect. The presence of BSA also greatly increased the error and caused the fluorescence to plateau at a lower serum concentration than was the case under other conditions. The effect of protein concentration on inhibition of antibody binding was confirmed by testing a constant dilution of antiserum against an increasing concentration of BSA. Inhibition of antibody-antigen binding, the increasing error with greater BSA concentration, and increased background fluoresence for normal serum were demonstrated (Text-fig. 4). 
P. L. Nayudu et al.

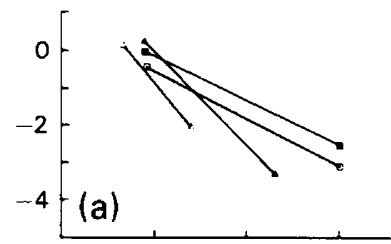

\begin{tabular}{lrrrrrr}
$\Delta$ PBS & 3.00 & 11.20 & 0.46 & 0.15 & $35.23^{*}$ & 0.55 \\
$\Delta$ PBS & 2.54 & 9.64 & 0.68 & 0.27 & $32.02^{*}$ & 1.43 \\
D Sucrose & 1.27 & 4.97 & 0.52 & 0.41 & $77.60^{*}$ & 0.63 \\
\hline Sucrose & 1.33 & 4.72 & 0.27 & 0.20 & $227.21 *$ & 0.38
\end{tabular}

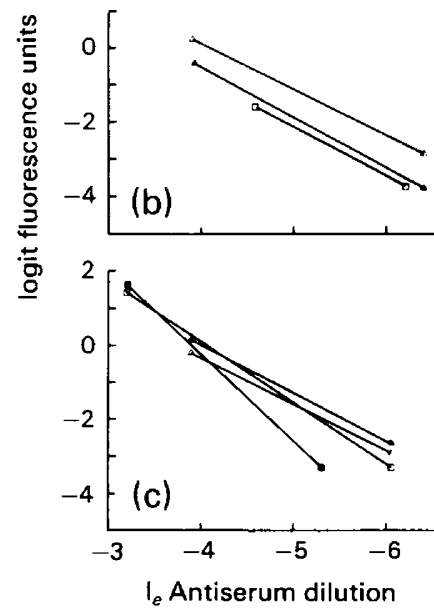

$\begin{array}{lrrrrrr}\text { A Glycerol } & 1.35 & 4.76 & 0.58 & 0.43 & 84.30^{*} & 0.81 \\ \begin{array}{l}\Delta \text { Sucrose-glycerol } \\ 1.22\end{array} & 4.96 & 0.75 & 0.62 & 42.79^{*} & 2.56 \\ \text { 口 BSA } & 1.36 & 4.61 & 0.96 & 0.70 & 6.02 * & 0.85\end{array}$

$\begin{array}{lllllll}\Delta \text { Sodium azide } & 1.33 & 5.40 & 0.24 & 0.18 & 188.51 * & 0.46\end{array}$

$\begin{array}{lllllll}\Delta \text { Heat inactivation } & 1.28 & 4.89 & 0.32 & 0.25 & 194.27^{*} & 0.32\end{array}$

$\begin{array}{lllllll}\text { - Formaldehyde } & 2.31 & 9.04 & 0.79 & 0.34 & 134.98^{*} & 1.59\end{array}$

$\begin{array}{lllllll}\text { 口Protein A } & 1.64 & 6.68 & 0.47 & 0.28 & 30.47^{*} & 0.01\end{array}$

Text-fig. 3. Effects of different conditions on results in the 4-day assay. $b=$ slope, $a=y_{x}^{0}, s=$ mean standard deviation of regression, $\lambda=$ index of precision. Linear regressions are derived from data. Values marked with an asterisk are significant at $P<0.05$ at least. (a) 0.05 M sucrose in phosphate-buffered saline (PBS) compared with PBS (no heat inactivation, no sodium azide), with IgG tracer. Single assays, except for sucrose which was triplicate pooled. (b) $7.5 \%$ glycerol, sucrose-glycerol, and $8 \%$ BSA, with IgG tracer. (c) $1 \%$ sodium azide, heat inactivation and $3.7 \%$ formaldehyde, prefixation of oocytes, with IgG tracer. Protein A tracer, sucrose in buffer,

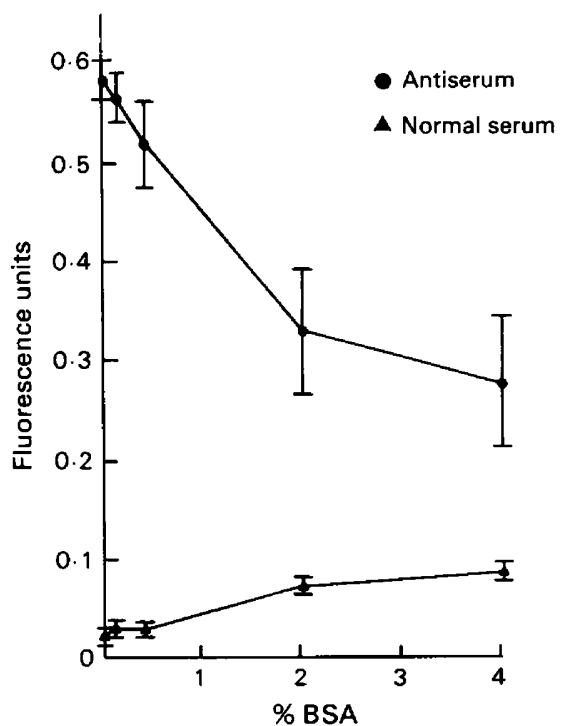

Text-fig. 4. Effect of protein (BSA) concentration; serum dilution 1:50, 4-day assay, no heat inactivation or sodium azide, IgG tracer, Values are mean \pm s.e.m. for 6 oocytes. 
Oocyte preservation was a significant factor in the assay. One means of achieving this was with sodium azide used at a concentration which inhibited degeneration but did not significantly affect the antibody-antigen binding. A trial of azide concentrations at a constant antiserum concentration showed $1 \%$ to be optimal. Neither $1 \%$ azide nor heat inactivation of the serum significantly affected the results, except for a slightly improved linearity with the latter (Text-fig. $3 c)$.

Fixation of oocytes in formaldehyde gave excellent preservation but altered binding properties. The assay sensitivity was greatly increased at the higher serum concentrations and reduced at the more dilute end, while fluorescence was not inhibited by high protein concentration.

When FITC-conjugated Protein A was used under standard conditions (Text-fig. 3c), the result was intermediate between that with formalin fixation and the normal sucrose-IgG assay. Protein A was not used routinely because the sensitivity at low antibody concentration was poorer under standard conditions than with IgG.

\section{The 3-day assay}

Because of its greater convenience and as part of a test to determine the effect of altering the incubation timings, a 3-day procedure was developed. An assay shorter than 3 days was difficult to carry out with large numbers of samples, and the results were less reliable, with a tendency towards considerably depressed fluorescence values and greater background interference. The preliminary standardizations were as described in the 4-day assay.

The effects of a standard concentration of sodium azide and heat inactivation, in combination and alone, were tested. The results were visualized with anti-rabbit IgG or Protein A. With FITC-IgG (Text-fig. 5a), the relatively large error and reduced differences between antiserum dilutions rendered detection of differences less sensitive, for the range used here, than with the 4-day assay or the 3-day assay with Protein A. Sodium azide and heat inactivation combined gave the most acceptable results for use with Protein A (Text-fig. 5b), which showed greater sensitivity at high antibody concentration than IgG. Therefore, these conditions were used for further tests.

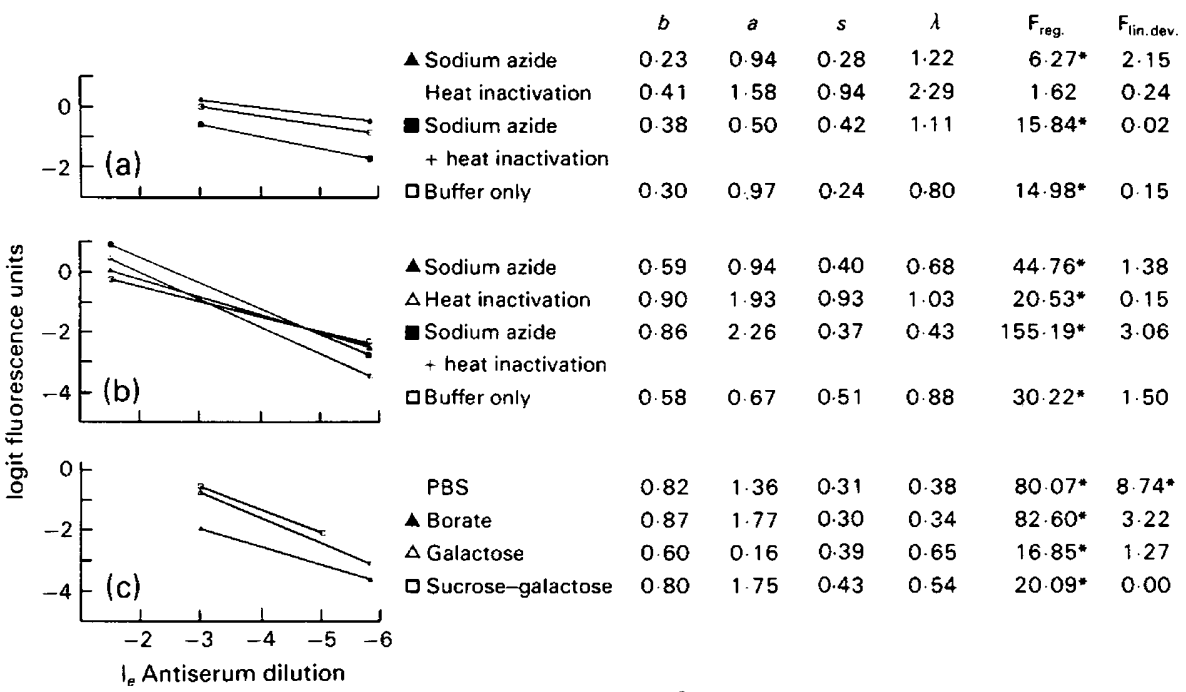

Text-fig. 5. Effects of different conditions on results in the 3-day assay. Linear regressions are derived from data. See Text-fig. 3 for abbreviations. ${ }^{*} P \leq 0.05$. (a) Sodium azide, and heat inactivation with IgG tracer, sucrose in buffer. (b) Sodium azide and heat inactivation with Protein A tracer, sucrose in buffer. (c) Phosphate buffered saline, borate buffer, 0.05 $\mathrm{M}$-galactose, and $0.05 \mathrm{M}$ sucrose-galactose with Protein A tracer. 
With PBS buffer, fluorescence was significantly less than with sucrose-PBS (Text-fig. 5c). Because the regression was not linear, it was not presented graphically. The replacement of PBS with borate-buffered saline resulted in a slight depression below standard sucrose buffer levels, and a plateau of fluorescence at high serum concentrations. Galactose in PBS generally inhibited fluorescence particularly at the high serum concentrations, but sucrose largely counteracted the galactose effect.

The control sera used to test the specificity of the assay were normal rabbit serum, rabbit anti-porcine spleen serum, and adjuvant-injected rabbit serum. None of these showed significant fluorescence and never caused a fluorescent ring on the surface of pig zonae pellucidae. The zona-positive antiserum and a normal serum were absorbed with washed porcine erythrocytes, spleen and liver cells. There was no significant effect on the fluorescence, indicating virtually no cross-reactivity between zona antibodies and antigens of the cells which were used in the adsorptions. The specificity of the labelled second antibody and Protein A were tested by incubation with washed untreated oocytes and by use in a normal assay after preadsorption with unlabelled anti-IgG or Protein A. No significant fluorescence was produced on the oocytes in either test.

Two antisera made against heat-solubilized zonae and acid-solubilized zonae were tested under optional Protein A 3-day and anti-IgG 4-day conditions. With heat-solubilized antiserum (Text-fig. 6) the regressions under both assay conditions were linear. Although the intensity of fluorescence was less than with the standard antiserum, the binding dynamics were similar. The results with the acid-solubilized antiserum differed significantly from the standard antiserum. The regressions, although significant, were non-linear (4-day, $b=2 \cdot 21, a=5 \cdot 68, s=0 \cdot 60, \lambda=$ 0.27 , regression $\mathrm{F}=109.09, P<0.001$; deviation from linearity $\mathrm{F}=22.13, P<0.001$; 3-day, $b=0.96, a=1.20, s=0.36, \lambda=0.38$, regression $\mathrm{F}=68.29, P<0.001$ : deviation from linearity $\mathrm{F}=4 \cdot 13, P<0.05$ ) and were therefore not represented in graphic form.

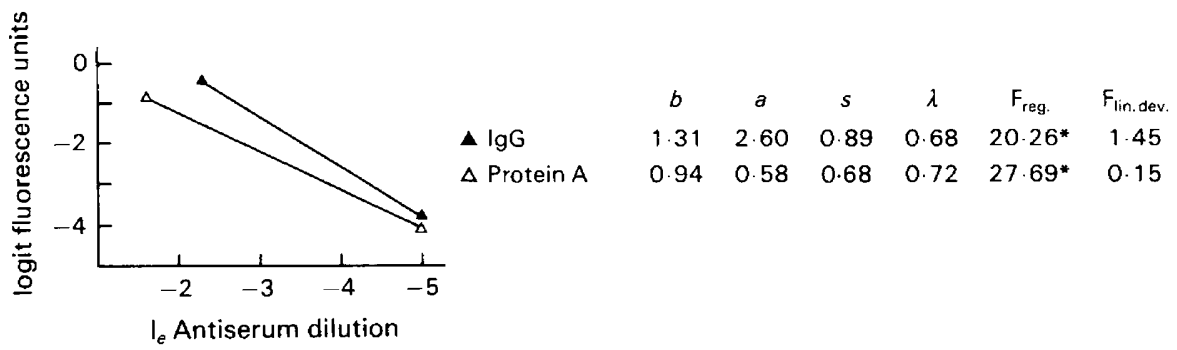

Text-fig. 6. Effect on antiserum against heat-solubilized zona, using IgG tracer in the 4-day assay and Protein A tracer in the 3-day assay. ${ }^{*} P \leq 0.05$.

\section{Discussion}

Dunbar et al. (1980) have suggested that the porcine zona pellucida is a complex mixture of microheterogeneous glycoproteins which appears to have intermolecular binding capacity. This, and the tendency to stick to glass, support the idea that the zona may bind a variety of molecules non-specifically. Yanagimachi, Nicholson, Noda \& Fujimoto (1973) reported that sialic acid is the major source of anionic residues in the hamster zona. Because anionic proteoglycans, in general, are known to bind interchain as well as with almost every other molecular type (Lindahl \& Höök, 1978), it was considered necessary to test a variety of assay conditions so that those which promoted maximal antigen-antibody binding and minimized competitive non-specific intermolecular interactions could be established.

The antibody titration curves differed greatly with the variables of the assay. The primary 
findings for 3- and 4-day tests are that: (1) sucrose has a beneficial effect on antibody binding to the intact zona, (2) all other test substances result in inhibition of antibody-antigen binding, (3) FITC-anti-IgG and FITC-Protein A have differing antibody binding capacities in this system, and (4) the duration of incubation and wash periods influence the assay results.

This assay is sensitive enough to detect differences in binding of antisera produced by injection of solubilized zonae, from that of the standard antiserum obtained by injection of entire zonae and oocytes. Heat solubilization did not significantly alter binding, with the exception of a general lowering of titre. However, acid solubilization greatly altered binding and the regressions were non-linear. The inference was that acid solubilization of zonae, but not heat, alters the antigenic structure in some way, thereby affecting the antibody's tendency to bind.

This system could be used for accurate titration of antibodies to porcine zonae pellucidae. Under standard conditions single dilutions could be used to monitor antibody binding, for example during immunization trials. Because the antigen is unaltered, this system may also be useful to study zona biochemistry.

We thank Dr B. Roberts for access to the Leitz fluorescent microscope. The International Planned Parenthood Federation supplied a part-time salary for L.E.F. and partly supported the project. P.L.N. is a Senior Research Officer of the National Health and Medical Research Council of Australia.

\section{References}

Borth, R. (1960) Simplified mathematics for multiple bioassays, Acta endocr., Copenh. 35, 454- 468.

Cornfield, J. (1970) Invalidity in bioassays. In Statistics in Endocrinology, pp. 145-162. Eds J. W. McArthur \& T. Colton. MIT Press, Cambridge, Massachusetts.

Dunbar, B.S. \& Raynor, B.D. (1979) A radioimmunoprecipitin assay for detection of antibodies to the zona pellucida. Biol. Reprod. 20, Suppl. 1, 87A, Abstr.

Dunbar, B.S., Wardrip, N.J. \& Hedrick, J.L. (1980) Isolation, physiochemical properties, and macromolecular composition of zona pellucida from porcine oocytes. Biochemistry, N.Y. 19, 356-365.

Gerrity, M., Niu, E.M. \& Dunbar, B.S. (1980) Alloimmunization of male and female rabbits with isolated rabbit zonae pellucidae. Biol. Reprod. 22, Suppl. 1, 96A, Abstr.

Gwatkin, R.B.L. \& Williams, D.T. (1978) Immunization of female rabbits with heat-solubilized bovine zonae: production of anti-zona antibody and inhibition of fertility. Gamete Res. 1, 19-26.

Gwatkin, R.B.L., Williams, D.T. \& Carlo, D.J. (1977) Immunization of mice with heat-solubilized hamster zonae: production of anti-zona antibody and inhibition of fertility. Fert. Steril. 28, 871-877.

Lindahl, U. \& Höök, M. (1978) Glycosaminoglycans and their binding to biological macromolecules. $A$. Rev. Biochem. 47, 385-417.

Oikawa, T. \& Yanagimachi, R. (1975) Block of hamster fertilization by anti-ovary antibody. J. Reprod. Fert. 45, 487-494.

Palm, V.S., Sacco, A.G., Syner, F.N. \& Subramanian, M.G. (1979) Tissue specificity of porcine zona pellucida antigens tested by radioimmunoassay. Biol. Reprod. 21, 709-713.

Shivers, C.A., Genozian, N., Franklin, S. \& McLaughlin,
C.A. (1978) Antigenic cross-reactivity between human and marmoset zonae pellucidae, a potential target for immunocontraception. J. med. Primatol. 7 , $242-248$.

Svensson, S., Hammarström, S.G. \& Kabat, E.A. (1970) The effect of borate on polysaccharide-protein and antigen-antibody reactions and its use for the purification and fractionation of cross-reacting antibodies. Immunochemistry, 7, 413-422.

Trounson, A.O., Shivers, C.A., McMaster, R. \& Lopata, A. (1980) Inhibition of sperm binding and fertilization of human ova by antibody to porcine zona pellucida and human sera. Arch. Androl. 4, 29-36.

Tsunoda, Y. \& Sugie, T. (1979) Inhibitory effect on fertilization in vitro and in vivo by zona pellucida antibody and the titration of this antibody. In Recent Advances in Reproduction and Regulation of Fertility, pp. 123-132. Ed. G. P. Talwar. Elsevier/ North Holland Biomedical Press, Amsterdam.

Tsunoda, Y., Sugie, T. \& Mori, J. (1979) Quantitative determination of titres of anti-zona serum. J. exp. Zool. 207, 315-320.

Vaitukaitis, J., Robbins, J.B., Nieschlag, E. \& Ross, G.T. (1971) A method of producing specific antisera with small doses of immunogen. J. clin. Endocr. Metab. 33, 988-991.

Yanagimachi, R., Nicholson, G.L., Noda, Y.D. \& Fujimoto, M. (1973) Electron microscopic observations of the distribution of acid anionic residues on hamster spermatozoa and eggs before and during fertilization. J. Ultrastruct. Res. 43, 344-353.

Yanagimachi, R., Winkelhake, J. \& Nicholson, G.L. (1976) Immunological block to mammalian fertilization: survival and organ distribution of immunoglobulin which inhibits fertilization in vivo. Proc. natn. Acad. Sci., U.S.A. 73, 2405-2408. 